\title{
Complutum
}

ISSN: 1131-6993

\section{Museos y sitios arqueológicos: miradas sobre el contexto de Brasil}

\author{
Alejandra Saladino ${ }^{1}$
}

Recibido: 15/03/2021 / Aceptado: 29/07/2021

Resumen. Ya sea en el ambiente urbano o rural, desde los yacimientos y los museos, se puede acceder a los restos materiales y a las memorias de las sociedades del pasado. La Carta de Nueva Delhi recomienda la creación de museos -o pequeñas entidades de carácter educativo- para presentar a los visitantes los vestigios arqueológicos de los sitios más destacados. Interrogándose si nos preguntamos sobre las políticas y las prácticas museísticas dirigidas a la preservación y socialización de sitios arqueológicos en Brasil, se observan realidades muy distintas, derivadas de aspectos como, por ejemplo, la vinculación y los compromisos estatutarios respecto a los sitios, los objetivos estratégicos y las prioridades institucionales y aun la relación entre museo, yacimiento y comunidades del entorno. El presente artículo tiene por objetivo presentar un panorama sobre la preservación del patrimonio arqueológico en el país desde una muestra de la diversidad arqueológica y museística que representan sus cinco regiones. Obsérvese que, pese a todas las dificultades y desafíos, los vínculos entre el museo y el sitio arqueológico van más allá del compromiso con la socialización del pasado porque son dirigidos hacia el presente y al futuro y porque buscan tratar de los derechos culturales y la sostenibilidad.

Palabras Clave: Patrimonio Arqueológico, Gestión, Interpretación, Musealización

\section{[en] Museums and archaeological sites: views on the context of Brazil}

Abstract. Whether in urban or rural settings, you can access material remains and the memories of past societies from sites and museums. The Charter of New Delhi recommends the creation of museums -or small interpretation centersto present to visitors the archaeological remains of the most outstanding sites. Wondering about museum policies and practices aimed at the preservation and socialization of archaeological sites in Brazil, it could be observed very different realities, derived from aspects such as, for example, the linkage and statutory commitments regarding the sites, the strategic objectives and the priorities of the institution and even the relationship between museum, site and surrounding communities. This article aims to present an overview of the preservation of archaeological heritage in the country from a sample of the archaeological and museum diversity that its five regions represent. Note that, despite all the difficulties and challenges, the links between the museum and the archaeological site go beyond the commitment to socializing the past because they are directed towards the present and the future and because they seek to address cultural rights and sustainability.

Keywords: Archaeological Heritage, Management, Interpretation, Musealization

Sumario. 1. Introducción. 2. Arqueología y museos en Brasil: una mirada a vuelo de pájaro. 3. Museos y sitios arqueológicos en Brasil: una pequeña muestra de la diversidad arqueológica y museística. 3.1. El Museo del Sambaqui de Joinville, Joinville, Santa Catarina (Región Sur del Brasil): arqueología y museología como compromiso social. 3.2. El museo de arqueología de Itaipu, Niterói, Río de Janeiro (Región Sureste): estratigrafía de la relación ser humano y ambiente. 3.3. El museo antropológico de la Universidad Federal de Goiás (Región Centro-Oeste). 3.4. La Fundación Museo del Hombre Americano, Parque Nacional Serra de Capivara, Piauí (Región Noreste): contribuciones para nuevas narraciones sobre el poblamiento del continente americano. 3.5. El Instituto de Investigaciones científicas y tecnológicas del Estado del Amapá (Región Norte): sobre el potencial científico y turístico del patrimonio arqueológico. 4. Notas finales. Agradecimientos. Bibliografía.

Como citar: Saladino, A. (2021): Museos y sitios arqueológicos: miradas sobre el contexto de Brasil. Complutum, 32(2): 459-475.

1 Universidad Federal del Estado de Río de Janeiro, Avda. Pasteur 458, Centro de Ciencias Humanas y Sociales, s.416, Urca, Rio de Janeiro, cep. 22290-240, Brasil, alejandra.saladino@unirio.br 


\section{Introducción}

Este artículo es el resultado de la reflexión provocada por la invitación para participar en el Congreso Internacional sobre Gestión del Patrimonio Arqueológico, tratando el tema de la relación entre Arqueología y museos en Brasil $y$, más concretamente, en el rol de esas entidades, en la gestión y la preservación de los sitios arqueológicos. El tema es uno de los conjuntos de intereses compartidos con colegas de distintas instituciones (Saladino y Polo 2017; Saladino y Castillo Mena 2018a, 2018b; Reis y Saladino 2018) y de investigaciones basadas en perspectivas teóricas y enfoques metodológicos de las ciencias humanas y sociales, concretamente, de la Arqueología, de la Museología y de las Ciencias Políticas.

Son muchas y distintas las relaciones entre museos y sitios arqueológicos dirigidas hacia la puesta en valor, la preservación, la interpretación y la comunicación de los yacimientos. Todas ellas tratan de seguir las Recomendaciones de Nueva Delhi (UNESCO 1956) respecto a la facilitación del acceso a las colecciones para el desarrollo de estudios comparativos, al mantenimiento de equipos administrativos y de expertos para garantizar la conservación de los materiales y a la creación de entidades cercanas a los sitios, para promocionar la comunicación del patrimonio. De la Península Ibérica, se destacan dos casos referentes a dos sitios prehistóricos, declarados Patrimonio Mundial por su marcada importancia científica. En Portugal, es emblemático - desde una perspectiva sociológica, política y arqueológica (Gonçalves 2001) - el proceso de patrimonialización de los grabados rupestres desplazados por el valle del río Coa y de su comunicación desde el Museo del Coa. En España se destacan Atapuerca, con su complejo de interpretación y socialización (constituido por los yacimientos de la Sierra de Atapuerca, el Museo de la Evolución Humana y el Centro de Arqueología Experimental) y también el complejo de Mérida, gestionado por el Consorcio Ciudad Monumental de Mérida.

De América del Sur se puede destacar dos sitios con museos dedicados a su preservación y a la recepción del público. En Brasil, el Museo de Misiones, el primer museo regional creado bajo la gestión del Instituto del Patrimonio Histórico y Artístico Nacional/IPHAN (desde 2009 está gestionado por el Instituto Brasileño de Museos/IBRAM), que presenta la historia de la Misión Jesuítica de San Miguel, declarada Patrimonio Mundial por UNESCO. En Perú, se recalcan los proyectos de sostenibilidad desarrollados con las comunidades locales y el Museo de Pachacamac, que interpreta y preserva el sitio con mismo nombre.

Esta pequeña muestra representa distintas realidades, retos y soluciones para la preservación y la puesta en valor del patrimonio arqueológico, derivadas de diferentes contextos políticos, económicos y sociales. Sin embargo, resultan también de variadas visiones sobre los museos, la interpretación del patrimonio cultural y la relación entre bienes culturales, territorio y personas.

Con este artículo se pretende enseñar el panorama de la preservación del patrimonio arqueológico en Brasil, enfocando el rol de los museos en la gestión y la socialización de los sitios arqueológicos. El análisis se estructura desde una muestra de cariz regional para subrayar el inmenso desafío de preservar, valorar y socializar una cantidad descomunal de sitios desplazados en un territorio nacional enorme, de muy distintas condiciones sociales, económicas y de preservación de los bienes culturales.

Es importante marcar el carácter complejo de los conceptos clave de este texto, museo y sitio arqueológico, pese a la existencia de definiciones oficiales y consolidadas en el campo científico. No son fáciles de capturar en declaraciones consensuales, mucho menos en estos momentos de revisiones frente a temas y reclamos actuales, como la cuestión de género, los derechos culturales y sociales de comunidades marginadas y/o invisibilizadas. Sobre el concepto de museo, hay que subrayar el momento presente, en el cual el sector museístico, desde el Consejo Internacional de Museos (ICOM), intenta crear una definición que aúne las características y funciones a los valores y las visiones de la entidad, acordes a las demandas e ilusiones del siglo XXI y que, a su vez, sea representativo en nivel internacional. Mientras se elaboraba este texto, el ICOM organizaba reuniones para consensuar una nueva definición, tras el rechazo del texto presentado en el congreso de ICOM, realizado en septiembre de 2019, en Japón. En el caso de la definición de sitio arqueológico, Nuno Bicho (2011) recalca la relación entre objetivos, miradas, enfoques teóricos, metodologías e intereses de las/los científicas/os y reconocimiento de la dimensión arqueológica del territorio. No hay intención de deshacer, tampoco de reducir, 
la complejidad del tema de los conceptos de museo y de sitio arqueológico. Sin embargo, hay que seleccionar una perspectiva. Por ello, este texto se sostiene en los discursos oficiales y de cariz normativa que, a su vez se apoyan en miradas más o menos consensuadas del campo científico.

El concepto de museo aquí adoptado se ubica en el Artículo $1^{\circ}$ de la Ley $n^{\circ} 11.904 / 09$ (el Estatuto de Museos, reglamentado por la Resolución $n^{\circ} 1824 / 13$ ), a la vez en consonancia con la actual definición del ICOM. Según la norma, los museos:

... son instituciones sin ánimo de lucro que conservan, investigan, comunican, interpretan y exhiben, con fines de conservación, estudio, investigación, educación, contemplación, y turismo, colecciones de valor histórico, artístico, científico, técnico o de cualquiera otra índole cultural, abierta al público, al servicio de la sociedad y de su desarrollo.

Párrafo único: Esta Ley insertará las instituciones y los procesos museológicos orientados a trabajar el patrimonio cultural y el territorio con miras al desarrollo cultural, socioeconómico y la participación comunitaria. (Art. $1^{\circ}$ de la Ley $n^{\circ} 11.904 / 09$ ).

Aquí se considera una definición más amplia, desde la cual la organización se caracteriza por los procesos de musealización (acciones de preservación, investigación $\mathrm{y}$ comunicación) sobre los bienes culturales. En consecuencia, no hace falta que la entidad se autodenomine museo para que se identifique como tal.

El concepto de sitio arqueológico aquí utilizado está en la Resolución IPHAN, $n^{\circ} 355 / 2019$, que establece los procedimientos para identificación y reconocimiento de sitios por parte de ese instituto:

Art. $2^{\circ}$ Para fines de esta Resolución, sitio arqueológico es el lugar donde se encuentran vestigios resultantes de actividades humanas, del período precolonial o histórico, ubicados en la superficie, subsuperficie o sumergidos, susceptibles de contextualización arqueológica.

El presente artículo está estructurado de forma que muestra un breve panorama sobre la relación entre Arqueología y Museos en el país. Los datos sobre el vínculo entre museos y sitios arqueológicos resultan de una recogida de in- formaciones desde fuentes estatales (el Catastro Nacional de Sitios Arqueológicos y el Registro de Museos $^{2}$ - CNSA) y también de la colaboración entre miembros de la Red de Museos y Acervos Arqueológicos y Etnológicos (REMAAE) y el Grupo de Trabajo Acervos de la Sociedad de Arqueología Brasileña (GTA/SAB).

El esfuerzo colectivo de identificar los sitios arqueológicos tratados desde procesos de musealización, integrales o parciales, resultó en reconocer estimadamente en torno a trescientos sitios en Brasil. En él se puede observar una gran diversidad respecto a la relación entre museo y sitio arqueológico y el rol de esa entidad en la preservación y la socialización de ese bien cultural. Para representar las cinco regiones del país, fueron seleccionadas cinco organizaciones que aplican acciones características de la musealización, mostradas en la Figura 1.

La muestra fue seleccionada con el objetivo de enseñar la variedad de experiencias, que tienen que ver con distintos aspectos, como por ejemplo, la vinculación entre organización y sitio arqueológico, los objetivos estratégicos de las entidades respecto a los monumentos y la diversidad de resultados de los procesos de socialización. Desde ahí, se discuten los desafíos de la gestión y puesta en valor de esos bienes culturales y la importancia de conjugar las políticas públicas de patrimonio cultural y de museos para mejorar la gestión y las estrategias de socialización de los sitios.

\section{Arqueología y museos en Brasil: una mirada a vuelo de pájaro}

En Brasil, las relaciones entre museos y Arqueología se notan ya en los orígenes de ambos. A mediados del siglo XIX, los primeros estudios sobre las culturas antiguas fueron desarrollados por aquellas entidades, que organizaban expediciones y creaban colecciones. Los museos cumplen un rol importante en la conservación, la investigación y la comunicación del patrimonio arqueológico. En el país la Arqueología del siglo XXI es disciplinar como objeto de enseñanza, pero también interdisciplinar por su constitución teórico-metodológica (resultado de la importación y la adapta-

\footnotetext{
Véase http://portal.iphan.gov.br/sgpa/?consulta=cnsa y http:// museus.cultura.gov.br/busca/\#\#(global:(enabled:(space:!t),filterEntity:space)).
} 


\begin{tabular}{|c|c|c|}
\hline ESTADO & ENTIDAD & $\begin{array}{c}\text { SITIO(S) MUSEALIZADO(S) } \\
\text { DESDE ACCIONES DE LA } \\
\text { ENTIDAD }\end{array}$ \\
\hline & REGIÓN SUR & \\
\hline \multirow[t]{2}{*}{ Santa Catarina (SC) } & Museo de Sambaqui de Joinville & $\begin{array}{l}\text { Sambaquis ubicados en el centro } \\
\text { urbano de Joinville }\end{array}$ \\
\hline & REGIÓN SURESTE & \\
\hline \multirow[t]{2}{*}{ Río de Janeiro (RJ) } & $\begin{array}{l}\text { Museo de Arqueología de Itaipu/ } \\
\text { Instituto Brasileño de Museos }\end{array}$ & $\begin{array}{l}\text { Convento de Santa Teresa y Duna } \\
\text { Grande }\end{array}$ \\
\hline & REGIÓN CENTRO-OESTE & \\
\hline \multirow[t]{2}{*}{ Goiás (GO) } & $\begin{array}{l}\text { Museo Antropológico de la } \\
\text { Universidad Federal de Goiás }\end{array}$ & $\begin{array}{l}\text { Sitios asociados al paisaje del Río } \\
\text { Araguaia }\end{array}$ \\
\hline & REGIÓN NORESTE & \\
\hline \multirow[t]{2}{*}{ Piauí (PI) } & $\begin{array}{l}\text { Museo del Hombre Americano/ } \\
\text { Fundación del Hombre Americano }\end{array}$ & Sitos rupestres de Serra de Capivara \\
\hline & REGIÓN NORTE & \\
\hline Amapá (AP) & $\begin{array}{l}\text { Instituto de Investigaciones } \\
\text { Científicas y Tecnológicas del } \\
\text { Estado del Amapá (IEPA) }\end{array}$ & Rego Grande I/Calçoene \\
\hline
\end{tabular}

Figura 1. Instituciones y sitios arqueológicos por región. Fuente: recopilación de datos de la autora.

ción de principios, métodos y técnicas de otras áreas), multidisciplinar (por la producción del conocimiento arqueológico derivado de estudios y análisis de muchas disciplinas), y también transdisciplinar, en la actuación del profesional (Saladino et al. 2020: 55).

Respecto a la vocación transdisciplinar de esa ciencia, importa marcar una especificidad que se nota en el país: el desarrollo y la consolidación de una línea de actuación profesional y de investigación conocida por Musealización de la Arqueología. Concretamente, se trata de un campo, pero también de un método y una política. Es un campo transdisciplinar e incluso un método por desarrollarse desde los principios y las dinámicas de los procesos de musealización, ejecutados, a la vez, desde acciones articuladas de salvaguardia, investigación y comunicación basadas en distintas disciplinas como, por ejemplo, la Arqueología, la Museología, la Conservación y la Educación. Pero en Brasil, la Musealización de la Arqueología se configura también como política para la "difusión del conocimiento, tratamiento de los problemas de conservación y de educación de la memoria" (Bruno 2018: 118), vinculada a los grupos sociales marginados y vulnerables.

Sin embargo, el cariz político de este campo de reflexión, investigación y actuación se nota en la forma militante de proceder de las/os agentes. Desde 2008, profesionales de museos, agentes de patrimonio cultural e investigadores docentes se organizan en colectivos (la REMAAE y el GTA/SAB) que, a su vez, actúan en conjunto para plantear una pauta y demandar de las entidades estatales la creación e implantación de una agenda conjunta para afrontar los principales retos de la preservación y puesta en valor del patrimonio arqueológico.

Los desafíos para la preservación y puesta en valor del patrimonio arqueológico derivan de la "estratigrafía del abandono", pero también del rol secundario de las políticas públicas de cultura y de patrimonio en la agenda del Estado y los efectos de las presiones del campo político y económico sobre ellas. Estos son algunos de los retos más difíciles de afrontar con respecto al crecimiento exponencial de las colecciones arqueológicas en los almacenes de museos y otras entidades que se encargan de guardarlas, consecuencia, a su vez, del aumento de la Arqueología de Contrato por las licencias ambientales y ordenamiento del territorio. Esas entidades no presentan condiciones técnicas ni presupuestarias para lograr preservar, investigar y comunicar adecuadamente ese pa-

Estratigrafía del abandono es un término elaborado por la museóloga María Cristina de Oliveira Bruno, de la Universidad de San Paulo, para representar el rol secundario de la herencia cultural de los pueblos originarios y los bienes arqueológicos en las representaciones identitarias de la sociedad brasileña. 
trimonio. Otro desafío para las buenas prácticas sobre el patrimonio arqueológico es la producción y la comunicación, por parte de esas entidades, de narrativas más actualizadas e inclusivas y menos decimonónicas y prejuiciosas.

Sin embargo, hay que subrayar el esfuerzo de algunas entidades para lograr actuar desde buenas prácticas en el punto de vista social. Algunas de ellas resultan de experimentos conceptuales y metodológicos que asocian las perspectivas post-procesuales, la Arqueología Etnográfica, la Arqueología Pública y la Museología Social con métodos como la gestión y la curaduría compartida entre conservadores y representantes de pueblos indígenas, como, por ejemplo, la exposición temporal "Resistencia ya", producida por el Museo de Arqueología y Etnología de la Universidad de San Pablo junto a los indígenas de los pueblos Kaingang, Guarani Nhandewa y Terena (Cury 2020).

\section{Museos y sitios arqueológicos en Brasil: una pequeña muestra de la diversidad arqueológica y museística}

Brasil es un país de $8.516 .000 \mathrm{~km}^{2}$ de extensión, donde viven poco más de 209 millones de personas principalmente concentradas en la costa. Este territorio presenta paisajes marcados por una diversidad de sitios arqueológicos de gran valor patrimonial y científico. En la región Sur, se localizan los sambaquis monumentales, unos tipos de concheros de grandes dimensiones distribuidos por la costa, construidos por poblaciones pescadoras- recolectoras que allí vivieron hace unos cuatro mil años y en donde enterraron a sus ancestros. A pesar de que los sambaquis fueron explotados desde los tiempos coloniales para la extracción de las conchas y la producción de cal, aún existen algunos inmensos, como el Garopaba do Sul, con $26 \mathrm{~m}$ de altura y 12.000 $\mathrm{m}^{2}$, aproximadamente. Además de esas estructuras asociadas a grupos humanos dedicados a la pesca y la recolección, en el interior de la zona existen restos de grupos de cazadores recolectores, como las impresionantes viviendas subterráneas. Además, hay sitios arqueológicos históricos de relevancia más recientes, como las Misiones Jesuíticas de San Miguel Arcángel.

En la región Sureste también existe gran variedad sitios arqueológicos precoloniales, como los sambaquis, algunos datados hacia el siete mil a.C., los restos del complejo de cuevas de Lagoa Santa, en Minas Gerais (con restos humanos cuyos análisis presentaron dataciones de hace once mil años) y también estupendos sitios coloniales, referentes a la diáspora africana, como el Muelle del Valongo, declarado Patrimonio Mundial.

En la Región Centro-Oeste de Brasil existen grutas y cuevas con pinturas y grabados hermosos, además de otros sitios precoloniales como los talleres líticos y otros restos de los antepasados de los pueblos originarios y también de períodos más recientes, relacionados al contacto entre ellos y las poblaciones europeas. Algunos sitios precoloniales de la región presentan dataciones que también ponen en jaque la teoría de que la Cultura Clovis está relacionada con los primeros pobladores del continente americano. El sitio Santa Elina, en el Estado de Mato Grosso, tiene evidencias de presencia humana de hace 25 mil años.

En la región Noreste existen impresionantes sitios de arte rupestre, como la Piedra del Ingá, ubicada en el Estado de Paraíba, declarada bien de interés cultural del país. Sin embargo, hay otros registros arqueológicos históricos relacionados con la diáspora africana en América, como los restos del Quilombo de Palmares, ubicado en la Serra da Barriga, en el Estado de Alagoas.

La Región Norte también presenta destacada colección de sitios arqueológicos de gran valor científico y patrimonial, como los geoglifos del Estado de Acre, la cueva Pedra Pintada, en el Estado de Pará (con restos arqueológicos de más de 11 mil años de antigüedad), los impresionantes registros arqueológicos que apuntan la selva amazónica como una selva antropogénica, transformada por la ciencia de los pueblos originarios, y cerámicas de hermosa policromía asociada a distintas culturas.

Según los datos divulgados por las entidades estatales del patrimonio cultural (IPHAN e IBRAM), en Brasil existen 27.582 sitios arqueológicos (registrados por las/os arqueólogas/os y por las/los profesionales del IPHAN) y 3.899 museos (instituciones museológicas autodenominadas museos) (datos del Catastro Nacional de Sitios Arqueológicos y de Museusbr consultados en diciembre de 2020) ${ }^{4}$. En las

Catastro Nacional de Sitios Arqueológicos (http://portal. iphan.gov.br/sgpa/?consulta=cnsa) y Museusbr (http://museus.cultura.gov.br/busca/\#\#(global:(enabled:(space:!t),filterEntity:space). 
figuras 2 y 3 se presenta la distribución de sitios arqueológicos y museos, distribuidos en las cinco regiones del país. En el Catastro Nacional de Sitios Arqueológicos, herramienta de protección del patrimonio arqueológico desarrollada por el IPHAN, los sitios se clasifican en tres categorías: precoloniales (antes de la llegada de los grupos europeos), de contacto (referente a los primeros sitios donde las culturas originarias y europeas mantuvieron contacto) e históricos.

Se pueden clasificar de forma muy resumida los sitios arqueológicos, siguiendo las categorías del Catastro Nacional de Sitios
Arqueológicos. Estas categorías son: sitios precoloniales (anteriores al año 1492), contacto (relacionados con las zonas donde existen los restos asociados con los primeros contactos entre los pueblos originarios y las poblaciones colonizadoras europeas) e históricos. A su vez, en la base de datos MuseusBr, los museos se clasifican por tipos (tradicional/clásico; virtual, de territorio/ecomuseo; unidad de conservación ambiental y jardín zoológico, botánico, herbario, acuario y planetario) y por temas (artes, arquitectura y lingüística; antropología y arqueología; ciencias exactas, de la

\section{Sitios Arqueológicos - CNSA (octubre 2020)}

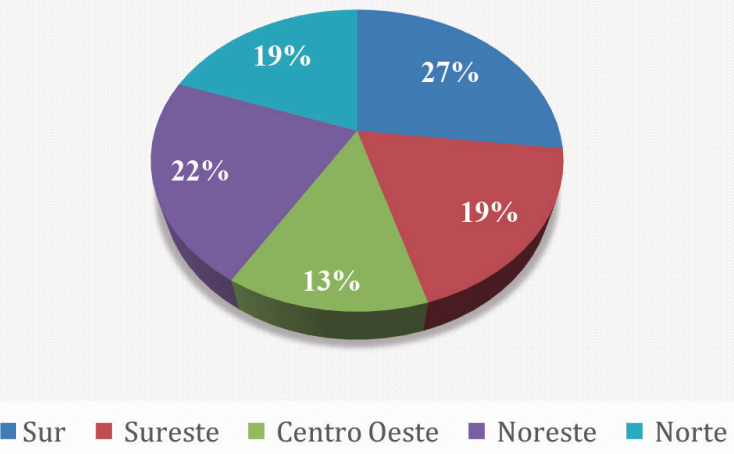

Figura 2. Gráfico de distribución de sitios arqueológicos por región de Brasil. Fuente: Catastro Nacional de Sitios Arqueológicos (consultado en octubre de 2020).

\section{Museos - Museusbr (octubre 2020)}

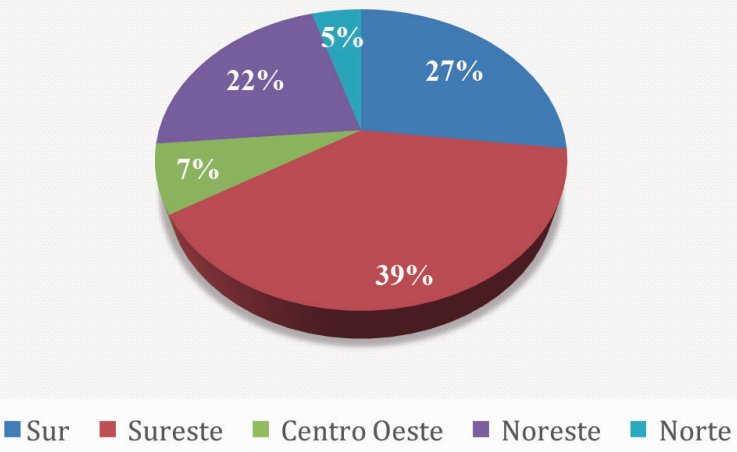

Figura 3. Gráfico de distribución de museos por región de Brasil. Fuente: Museusbr (consultado en octubre de 2020). 
tierra, biológicas y de sanidad; historia, educación, deporte y ocio; medios de comunicación y transporte; producción de bienes y servicios y defensa y seguridad pública).

Estas bases de datos no permiten identificar los museos que poseen colecciones arqueológicas, solamente los que están registrados como museos arqueológicos. Sin embargo, se puede observar la diversidad de realidades respecto a las entidades responsables de esos bienes, figuren o no en esa plataforma. Existen organizaciones más antiguas y tradicionales, con protocolos de gestión establecidos, pero también existen otras, como laboratorios y departamentos de universidades, además entidades cuyo acervo procede de las políticas de apoyo a los proyectos de investigación arqueológica.

Las bases de datos del IPHAN y del IBRAM presentan informaciones cuantitativas sobre los museos y sitios arqueológicos en todas las regiones y Estados de la nación, sintetizadas en la Figura 4:

\begin{tabular}{|l|c|c|}
\hline \multicolumn{1}{|c|}{ Región } & Museos & Sitios Arqueológicos \\
\hline Sur & 1.055 & 7.348 \\
\hline Sureste & 1.451 & 5.128 \\
\hline Centro-Oeste & 287 & 2.349 \\
\hline Noreste & 847 & 5.685 \\
\hline Norte & 182 & 3042 \\
\hline
\end{tabular}

Figura 4. Museos y Sitios Arqueológicos de Brasil (por región). Fuente: IPHAN e IBRAM (consultado diciembre 2020).

Estas bases de datos no presentan información respecto a los sitios arqueológicos musealizados o en proceso parcial de musealización (es decir, si son visitables o si son objeto de acciones educativas y de socialización). Para este tema, ha sido fundamental la colaboración de las/los miembros de la REMAAE y del GTA/SAB, pues desde ahí se pudo identificar un conjunto de sitios arqueológicos que pasan por proceso de musealización, mostrado en el siguiente gráfico.

Es importante subrayar que los procesos de musealización de sitios presentan distintos resultados por lo diferentes que son los objetivos, las coyunturas y los retos para sacarlos adelante. Luego, hay sitios arqueológicos abiertos al público con el apoyo de algunos instrumentos mínimos de comunicación, sitios musealizados donde el proceso de musealización ha sido completado y también los sitios musealizados que a su vez están integrados en proyectos más amplios de musealización de territorios.

Para este artículo, fue elaborada una muestra de sitios arqueológicos musealizados (integral o parcialmente) intencionalmente heterogénea. Se pretende enseñar, desde distintas realidades, la diversidad cultural precolonial plasmada en los sitios pero también la variedad de experiencias desde los procesos de musealización, que resultan en el acceso de los públicos a esta categoría de bienes culturales, presentada a continuación.

\subsection{El Museo del Sambaqui de Joinville, Joinville, Santa Catarina (Región Sur del Brasil): arqueología y museología como compromiso social}

El Museo de Sambaqui de Joinville (MASJ) es una entidad pública municipal ubicada en la ciudad de Joinville, en Santa Catarina. Fue fundado en 1972 (Gusso y Bandeira 2018), después que el ayuntamiento, con el objetivo de preservar, gestionar y difundir el patrimonio arqueológico de la región, comprara las colecciones y la biblioteca del arqueólogo amante de la zona, Guillermo Tiburtius.

El MASJ fue seleccionado para representar las relaciones entre museos y sitios arqueológicos de la región Sur del país por algunas especificidades. La primera se debe al compromiso institucional con la preservación de los sambaquis distribuidos en la zona urbana. Este pacto está declarado en su decreto de creación, lo que significa que su acervo es ex situ e in situ. Entonces, los sitios están integrados a los procesos museológicos y de curaduría del MASJ. Y la segunda se debe a su innovación en relación a la educación patrimonial, pues, desde los años 1970, desarrolla programas de educación patrimonial dedicados a la difusión y preservación de los sambaquis

Aunque las actividades educativas sean referencia nacional y logren alcanzar algunos resultados positivos para la conservación de los sitios, el tema de la relación entre comunidades y patrimonio arqueológico aún resulta complicado. El Sambaqui Morro do Ouro, ubicado en el Parque de la Ciudad, fue objeto de un proyecto para hacerlo visitable, con la creación de senderos de acceso hacia la cumbre, 


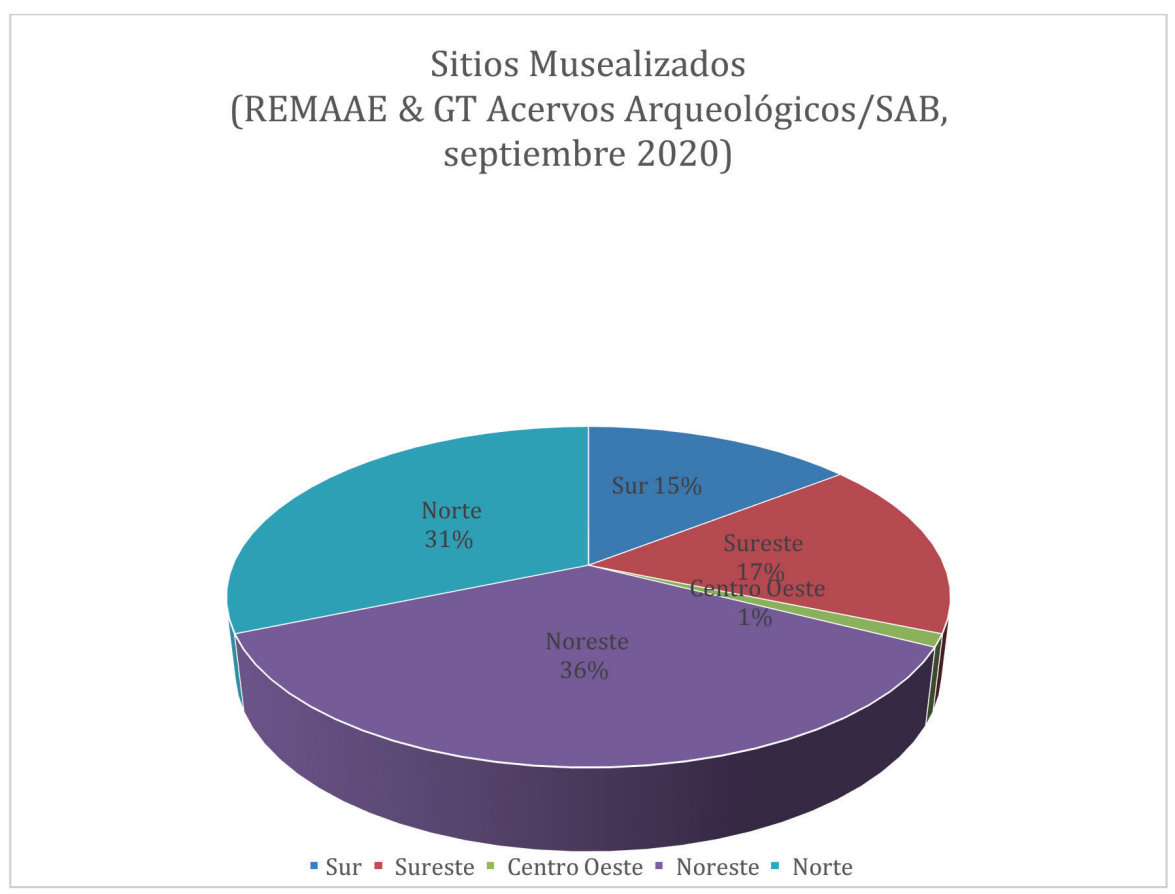

Figura 5. Gráfico con el número de sitios arqueológicos musealizados.

Fuente: encuesta del Grupo de Trabajo Acervos Arqueológicos de la Sociedad de Arqueología Brasileña y la Red de Museos y Acervos Arqueológicos y Etnográficos (consultado septiembre 2020).

donde se construyó un mirador (Costa 2019: 407). El equipo del museo monitoreó la reacción de los visitantes y los resultados del estudio indicaron que el sitio había sido preservado pero no las estructuras de acceso. Además, se identificó que al público no le interesaba leer la información sobre la arqueología del sitio que aparecía en los carteles dispuestos a lo largo de los caminos de acceso.

A su vez, el sambaqui Rio Comprido y el bosque del entorno son las áreas de ocio de una zona muy poblada de la ciudad (Machado 2013). El MASJ desarrolla actividades de educación patrimonial y de rescate. Pese a todos los esfuerzos de concienciación, el medio está en riesgo por los desechos tirados por los vecinos y también por las viviendas irregulares ahí construidas. El museo, frente a esas dificultades, trata de mejorar las acciones de educación patrimonial y ambiental.

Pese a la existencia de leyes municipales para proteger los sambaquis urbanos, la preservación y la gestión es todo un reto por los temas relacionados a la vida urbana, como, por ejemplo, la transformación de los sitios en depósitos de basura y lugares de consumo de drogas y de robos (Gusso y Bandeira 2018: 48). Le tocaría al equipo del museo intermediar los conflictos y encontrar soluciones, articuladas con los planes de urbanización y desarrollo local.

\subsection{El museo de arqueología de Itaipu, Niterói, Río de Janeiro (Región Sureste): estratigrafía de la relación ser humano y ambiente}

El Museo de Arqueología de Itaipu (MAI) es una entidad pública estatal ubicada en la ciudad de Niterói, en el litoral de Río de Janeiro. Fundado en 1977 como uno de los museos regionales vinculados al IPHAN, desde 2009 está vinculado al IBRAM. Ha sido creado para preservar y difundir el patrimonio arqueológico de la zona. Sin embargo, hoy en día también se dedica a preservar el patrimonio integral del área y también las memorias de las comunidades locales, como los pescadores tradicionales, fundamentando así sus acciones en la Museología Social.

El MAI fue elegido para representar la relación entre museos y sitios arqueológicos en Río de Janeiro por sus particularidades. En primer lugar, por tratarse de un sitio arqueológico: las ruinas del Convento de Santa Teresa, declaradas bien de interés cultural por el IPHAN. En segundo lugar, por su compromiso de preser- 
var y comunicar el patrimonio integral de la zona. En tercer lugar, por el sitio arqueológico Duna Grande - con restos de grupos de pescadores-recolectores de más de cinco mil años de antigüedad - siendo tomado como acervo del museo (Figura 6). En cuarto lugar, por su dedicación a la preservación de los restos del pasado y del presente (a través de acciones con las comunidades del entorno); todo eso para colaborar activamente en la construcción de un presente y un futuro más sostenible. De ahí se puede considerar que el MAI se trata de un museo de sitio pero que también está planeado, para actuar, desde acciones de preservación y educación, sobre el patrimonio integral de la zona.

El MAI ha sido tema de diversos estudios de temática histórica y patrimonial (Saladino et al. 2013, 2014; Ferreira 2017), sin embargo, queda mucho por investigar respecto al pasado colonial del Convento de Santa Teresa (construido en el siglo XVIII), pues los documentos son muy escasos y aún no han sido desarrolladas investigaciones arqueológicas, solamente algunas prospecciones superficiales.

La relación entre las comunidades del entorno y los bienes arqueológicos cuidados por el MAI es compleja. Se trata de un contexto lejano al centro de la ciudad, la playa, la laguna y la montaña, objeto de intereses inmobiliarios que resultaron desastrosos para la preservación del patrimonio integral. Aunque el museo desarrolle programas de educación patrimonial y socioambiental, principalmente para el público escolar (Figura 7), no todos los/ as vecinos/as colaboran en la preservación del valor patrimonial de los sitios arqueológicos, construyendo viviendas pegadas a las ruinas del convento (Saladino, Barata, Biserra 2014) o destruyendo los carteles que señalan e informan sobre el sitio Duna Grande.

Las últimas gestiones del museo fueron más comprometidas en la preservación del patrimonio integral de la zona (donde existe el Parque Ambiental de Sierra de Tiririca), asumiendo su papel en acciones políticas y culturales en colaboración con las comunidades locales, las distintas entidades culturales y la administración pública. El MAI promueve, apoya y participa en solicitudes y actuaciones relacionadas con la planificación urbana de la zona, la protección del medioambiente y el desarrollo; todos los sábados se organiza en frente del museo una feria con productos agrícolas y artesanía local.

El MAI, a pesar de sus limitaciones derivadas de los pequeños espacios para los depósitos y exposiciones, favorece un círculo virtuoso que resulta en el fortalecimiento de los vínculos entre museo y sociedad. Más que la realización de eventos educativos y culturales, importantes para que se cumpla su misión,

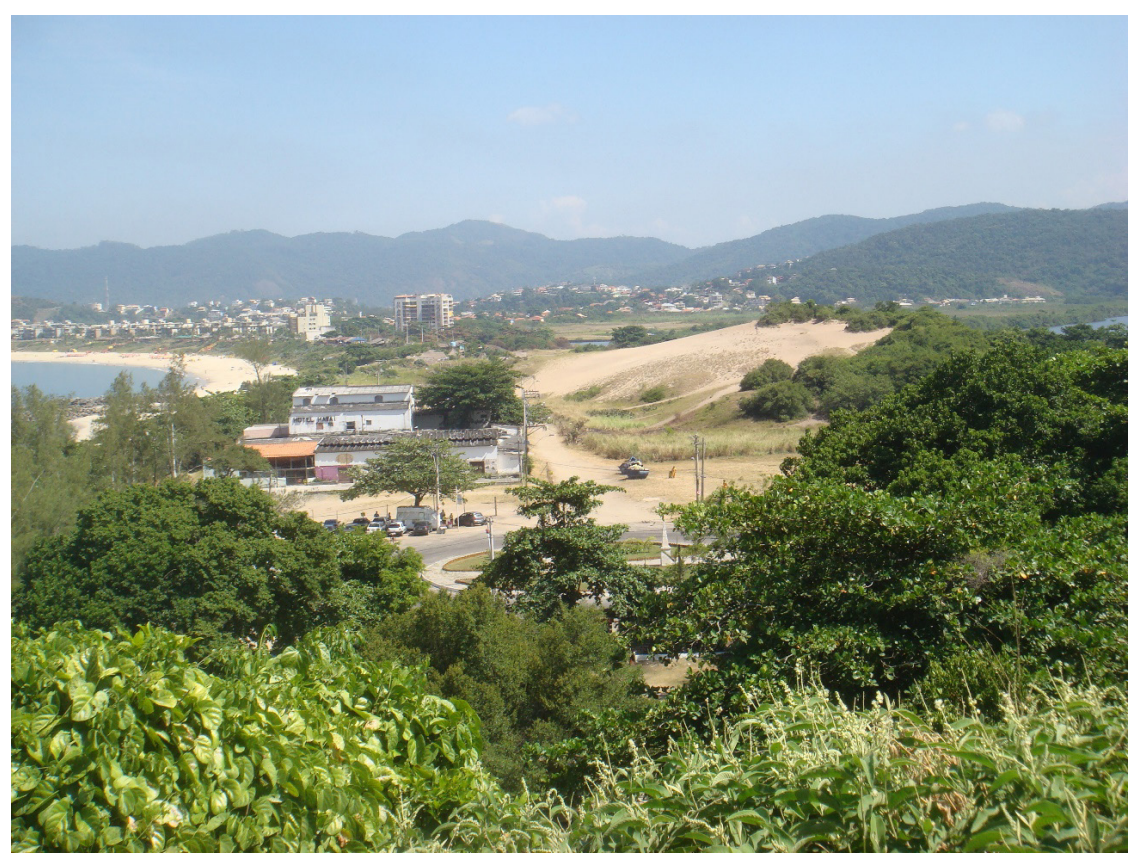

Figura 6. Imagen desde la Colina de Andorinhas al fondo se nota el yacimiento Duna Grande. Fuente: archivo personal de Alejandra Saladino. 


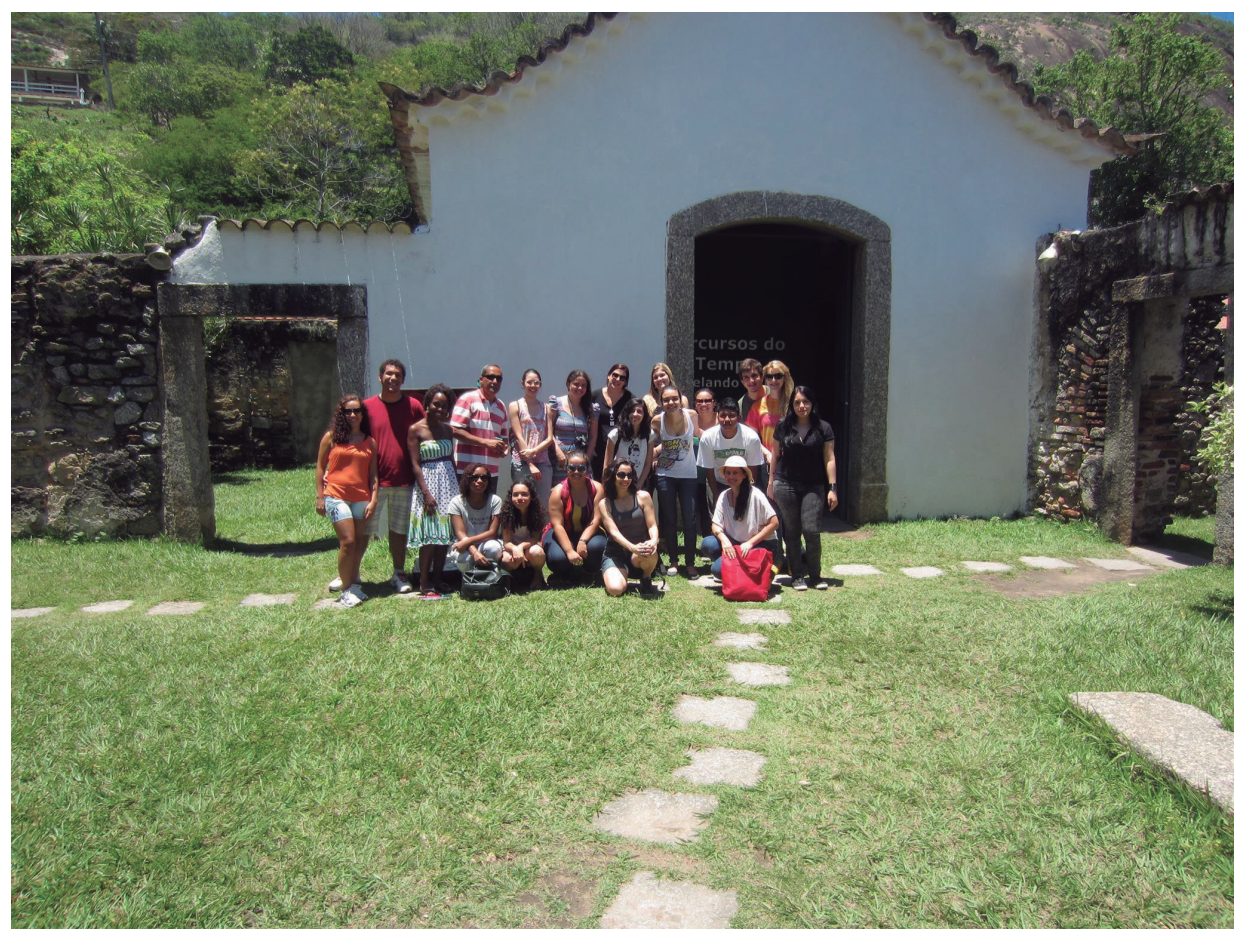

Figura 7. Estudiantes del Curso de Museología de la Universidad Federal del Estado de Río de Janeiro en visita al MAI.

Fuente: Archivo personal de Alejandra Saladino.

la entidad contribuye al fortalecimiento de la ciudadanía, asumiendo su papel como agente político que apoya las acciones frente a los conflictos de interés en la zona, resultantes de la especulación inmobiliaria y sus efectos negativos en el medioambiente (Saladino y Laroque 2020 ).

\subsection{El museo antropológico de la Universidad Federal de Goiás (Región Centro-Oeste)}

El Museo Antropológico de la Universidad Federal de Goiás (MA/UFG) es una entidad pública ubicada en la ciudad de Goiania, capital de Goiás. Fue creado en 1969 y desde entonces se encarga de preservar la cultura material y las memorias de las comunidades del pasado y del presente de la región, que son objetos de investigación de los docentes de la universidad y de otras entidades científicas. Sus colecciones etnográficas y arqueológicas resultan de la recolección de los/as investigadores/as de la universidad dedicados a la Antropología Social y Cultural, Educación Indígena, Arqueología, Etnolingüística, Museología y otras disciplinas.

Es importante destacar que fue elegido para representar la relación entre museo y sitio arqueológico del Centro-Oeste del país, justamente un caso que no fue nombrado en el mapeo desarrollado con las/os colegas de la REMAAE y del GTA/SAB. Se trata de una ocurrencia entre el MA/UFG y un importante territorio para las comunidades del pasado y del presente. Ubicado a los márgenes del río Araguaia, es objeto de investigación de un proyecto de la entidad, titulado "Río Araguaia: lugar de memorias e identidades", coordinado por Camila de Moraes Wichers, que consta en el plan museológico del museo (Martins 2017).

Este caso fue seleccionado por algunas de sus características. En primer lugar, porque se trata de una relación establecida desde un proyecto de investigación basado en la Museología Social, en la Arqueología Etnográfica y en la Arqueología Colaborativa, experimentando una práctica científica de cariz decolonial. Y en segundo lugar, porque la investigación toma por objeto un paisaje y no un sitio o un conjunto de ellos. Se pone en evidencia el paisaje cultural del Río Araguaia, contemplando su dimensión arqueológica, patrimonial y sociocultural. Luego, se trata de un conjunto de sitios arqueológicos insertos en un proyecto más amplio de musealización del territorio. Así, el MA/UFG investiga, interpreta y preserva la dimensión arqueológica de un territorio, pero 
articulándola con las memorias y las identidades de los grupos sociales para quienes el río Araguaia además de sagrado, es un ancestro.

El contexto de la investigación es un territorio indígena del Pueblo Karajá ${ }^{5}$, ubicado en el municipio de Aruanã, región este de Goiás. En el siglo XIX, este enclave tuvo rol estratégico para la expansión de las fronteras y la ocupación del interior del país, desde la navegación en el río (Moraes Wichers 2019). Algunas de las consecuencias socioculturales de ese avance fueron la evangelización forzada de las/os indígenas, los conflictos, la pérdida de hitos espaciales de memorias y la demarcación de los territorios del pueblo Karajá en Goiás y Mato Grosso, a fines del siglo XX.

La población Karajá es una agente activa en la investigación. Sus memorias y narrativas sobre su vínculo con el río son el eje central para la comprensión del paisaje, que está construido desde sus territorialidades, materialidades y las cosmologías (Moraes Wichers 2019: 64). Por ello, esas miradas y relaciones contribuyen para la experimentación y el perfeccionamiento de metodologías indisciplinadas que consideran los significados de los restos en el pasado y en el presente. Las metodologías indisciplinadas se caracterizan por la "distribución del conocimiento teórico y del mundo y la autonomía práctica del conocimiento respecto a las relaciones sociales/vitales" (Haber 2011: 17), subjetivando, a partir de otros lugares que no son aquellos que institucionalmente resultan en la construcción del privilegio epistémico; esos lugares serían de reconocimiento, de aprendizaje y de solidaridad (ibid. 18).

Desde los años 1970, el territorio cuyo epicentro es el río ha sido investigado por arqueólogas/os vinculados al MA/UFG. Por eso, es objetivo de Wichers (2019) identificar los sitios ya registrados e investigados, los impactos de los estudios en las memorias de las personas y en el mismo proceso de demarcación de los territorios indígenas, pero también recolectar materiales sumergidos y en la orilla del río.

La Museología Social y la Arqueología Colaborativa se concretan en la Musealización de la Arqueología, pues el proyecto propone un modelo de gestión comunitaria de los restos

El pueblo Karajá, autodenominado Iny (nosotros mismos) y lingüísticamente vinculado al tronco Macro-Jê, tiene relación secular con el río Araguaia, ocupando sus márgenes, extendidas hoy en día en las regiones Centro-Oeste y Norte de Brasil. Más información sobre el tronco Macro-Jê, véase en Martins et al (2015). arqueológicos, desde el registro de memorias de los territorios indígenas y desde las peticiones de los indígenas como, por ejemplo, el apoyo para la conservación, curaduría y exposición de piezas de un museo comunitario en territorio Karajá y luego la institucionalización de esa entidad.

De esta manera, el museo establece una relación con el patrimonio del paisaje del río Araguaia fundada en el diálogo intercultural y desde una praxis científica y patrimonial decolonial.

\subsection{La Fundación Museo del Hombre Americano, Parque Nacional Serra de Capivara, Piauí (Región Noreste): contribuciones para nuevas narraciones sobre el poblamiento del continente americano}

La Fundación Museo del Hombre Americano (FUMDHAM) es una entidad civil y sin ánimo de lucro ubicada en la ciudad de San Raimundo Nonato, Sureste del Piauí. Fue creada en 1986 para cuidar del patrimonio integral del Parque Natural de Serra de Capivara, fundado en 1979. En ese paisaje de clima semiárido y de impresionante singularidad geomorfológica existen los más hermosos paneles pintados de la región, por la cantidad y por la expresividad de las figuras. Esos y otros registros arqueológicos del parque, declarado bien de interés cultural y también Patrimonio Mundial de UNESCO, son objeto de investigaciones desde los años 1970 y poseen valor científico incalculable, pues contribuyen para relativizar la teoría de que los primeros grupos a ocupar el continente están relacionados a la Cultura Clovis (Lourdeau 2019). Entonces, esos restos son fundamentales para la creación de nuevas narrativas sobre el poblamiento de las Américas.

En el parque, con 129.140 hectáreas (Sanabria 2018: 228), se ubica la mayor parte de pinturas rupestres de la región Noreste (Saladino, Wichers, Sanabria 2015), de cuya preservación está encargada la FUMDHAM. Para lograrlo, ha celebrado colaboraciones con distintas entidades nacionales e internacionales.

Esta entidad, vinculada al Instituto de Arqueología, Paleontología y Ambiente del Semiárido del Noreste de Brasil, desarrolla actividades científicas y culturales en distintas áreas. Las colaboraciones entre instituciones nacionales e internacionales han propiciado a la FUMDHAM una estructura con laborato- 
rios, almacenes, auditorio y anfiteatro. Desde esas colaboraciones y ayudas se creó un banco de datos y una publicación científica, la Revista Fumdhamentos, dedicada a divulgar las investigaciones sobre el parque y otros temas de interés ${ }^{6}$.

Sin embargo, la creación del parque y la musealización de parte de los registros arqueológicos de la zona derivaron en la desterritorialización y consecuentes conflictos entre el parque y las familias que allí vivían y cazaban, poniendo en riesgo la protección de la flora, de la fauna y también del patrimonio cultural. Para afrontar esos retos, la $\mathrm{FUMDHAM}^{7}$, ha desarrollado diversas acciones sociales para el desarrollo local, a través de la integración entre comunidad local y patrimonio integral.

La FUMDHAM fue seleccionada para representar la relación entre museo y sitio arqueológico del Noreste del país por algunas condiciones. En primer lugar, por los valores científicos y patrimoniales del conjunto de sitios de arte rupestre. Luego, la destacada actuación de la institución, responsable por la política de preservación del parque. Esta entidad desarrolla distintos y destacados programas y proyectos de investigación, y de socialización y educación, aparte de haber creado en la zona dos museos, el Museo del Hombre Americano (MHA), fundado en 1998, y el Museo de la Naturaleza, fundado en 2018.

El visitante accede al MHA/FUMDHAM, dedicado a mostrar los modos de vida que transformaron el paisaje, las investigaciones desarrolladas hace poco más de 40 años y la gran biodiversidad de la zona, A continuación, el público puede hacer el recorrido por el extenso circuito museográfico in situ con 14 rutas turísticas, donde se muestran 103 pinturas. Entonces se trata de la relación entre un museo tradicional (el MHA/FUMDHAM, inaugurado en 1988) y un conjunto de registros musealizados in situ, legados por las investigaciones arqueológicas, coordinadas por Niède Guidon, e insertos en un proyecto de patrimonio integral de cariz preservacionista pero a la vez turística. Por tanto el rol del museo es estratégico, pues trata de divulgar las investigaciones desarrolladas en los sitios desplazados por el parque pero también preservarlos desde la comunica-

Véase http://fumdham.org.br/fumdhamentos/

Respecto a las relaciones entre comunidades y patrimonio del Parque Nacional de Serra de Capivara véase Saladino et al. (2015) y Sanabria (2018). ción museológica, las acciones educativas y el turismo ecológico.

\subsection{EI Instituto de Investigaciones científicas y tecnológicas del Estado del Amapá (Región Norte): sobre el potencial científico y turístico del patrimonio arqueológico}

El Instituto de Investigaciones Científicas y Tecnológicas del Estado del Amapá (IEPA) es una entidad pública ubicada en la ciudad de Macapá, capital del Amapá. Su trayectoria está vinculada a la creación de diversos museos en la zona ya en los años $1960^{8}$. Sin embargo, el IEPA fue fundado en 1991, como entidad técnica, administrativa y financiera, y con patrimonio y presupuestos propios.

A lo largo de los años, el instituto ha pasado por reestructuraciones para lograr alcanzar su misión de producir y difundir conocimientos científicos y tecnológicos sobre el ser humano, la flora, la fauna y el medioambiente del Amapá y, de esa manera, contribuir para su desarrollo económico y social.

Aunque no se autodenomine museo, dicha institución ha sido seleccionada para representar la relación entre esa categoría de organización y los sitios arqueológicos de la región Norte del país por sus destacados esfuerzos para la producción de conocimiento, la preservación y la comunicación del patrimonio arqueológico del Amapá. Además, desde sus sectores de Arqueología y Museología, el IEPA desarrolla típicas actividades de los procesos de musealización.

En la primera década del siglo XXI, el personal del instituto visitó un área cercana a la ciudad de Calçoene, que parecía tratarse de un sitio megalítico con más de 120 monumentos de granito, algunos de ellos con más de $3 \mathrm{~m}$ de largo, desplazados de manera a formar un círculo. Mariana Cabral y João Saldanha (2008a; 2008b; 2009) observaron que uno de los monumentos había sido dispuesto que no creara sombra durante el solsticio de invierno. Posteriormente, las interpretaciones sugieren la posible función astronómica del sitio, construido entre dos mil y mil años a.C., pero también una función ritual, pues hay enterramientos allí.

Los valores científico y patrimonial del monumento, nominado Rego Grande I (la comu-

Véase http://www.iepa.ap.gov.br/instituicao.php. 
nidad del entorno lo llama de Calçoene), luego fueron reconocidos, incluso por el sector político local. Interesado en explotar el potencial económico del bien cultural, intensificando el turismo en la zona, el gobierno del Estado apoyó la creación de un parque y de un museo para preservar y socializar el sitio. Luego, el IEPA empezó a desarrollar proyectos de investigación y difusión del monumento.

La investigación arqueológica iniciada por el IEPA tenía en cuenta la posibilidad de socialización del monumento, por su valor excepcional. A través de una colaboración entre esa entidad, el IPHAN y otras (como el Museo Paraense Emilio Goeldi), se elaboró un proyecto para musealizar la zona, de carácter multidisciplinar y fundamentado en un estudio de viabilidad, teniendo en cuenta aspectos como el acceso, valor patrimonial y conservación del monumento, interés de la comunidad local en el proyecto de musealización y potencial para impulsar el desarrollo local.

Aunque la propuesta tuviera todo el apoyo de la sociedad, y pese a la fundamentación teórico-metodológica en Arqueología Pública y en Museología Social, frente a los cambios políticos sucedidos a lo largo del tiempo el proyecto ya no contaba con el soporte del gobierno local y no arrancó. Sin embargo, considerando los valores científicos y patrimoniales del sitio arqueológico y la calidad del proyecto desarrollado, en un momento político y económico más favorable, la musealización del monumento podría realizarse.

\section{Notas finales}

La muestra que representa el rol de los museos y demás entidades dirigidas a la preservación del patrimonio arqueológico fue seleccionada con el objetivo de mostrar la variedad de experiencias y procesos y, desde ahí, la complejidad de la preservación del patrimonio arqueológico y el papel estratégico de aquellas entidades en ello. Distintas organizaciones, con sus características y vinculaciones institucionales, trayectorias, misiones, objetivos, metodologías y recursos humanos y presupuestarios, afrontan el reto de conservar, investigar y difundir los igualmente peculiares sitios arqueológicos (precoloniales, históricos o paisajes culturales; clasificados como bienes de interés cultural, como Patrimonio Mundial o simplemente reconocidos como patrimonio por las comunida- des locales; integrados en reservas ambientales, el tejido urbano o ubicados en territorios indígenas patrimonializados; de fácil acceso o alejados de las zonas urbanas etc).

Pese a las diferencias de estructura, forma y vinculación institucional, las entidades seleccionadas están comprometidas con la preservación, la gestión y la divulgación del patrimonio arqueológico, directamente, con los sitios recopilados en este artículo. Para ello, realizan acciones relacionadas con el proceso de musealización, donde destacan las actividades educativas. Los efectos son igualmente muy distintos debido a las coyunturas específicas de cada institución.

El MASJ se trata de una entidad comprometida legalmente con la gestión de los sambaquis urbanos de Joinville. A pesar de su experiencia en ello, resultado de diversos proyectos desarrollados a lo largo del tiempo, queda mucho por hacer respecto a la sensibilización de la sociedad sobre su responsabilidad en la preservación del patrimonio arqueológico. Para lograr mejores y más duraderos resultados, se necesita que las/os agentes involucradas/os (principalmente las comunidades), participen activamente en la toma de decisiones respecto a los planes de gestión de los sitios y que estos estén articulados e integrados en los planes de urbanización y desarrollo de la ciudad.

El MAI afronta retos parecidos respecto a la relación entre comunidades y sitios arqueológicos, en especial el Duna Grande, que los fines de semana se transforma en mirador $y$ vertedero.

E1 MA/UFG desarrolla una relación innovadora con los sitios arqueológicos investigados, por dos aspectos. Primero por tomar el río Araguaia como "espacio de sociabilidades desde una perspectiva interdisciplinar, implicando un enfoque arqueológico, una intervención museológica y una mirada etnográfica, al mismo tiempo en que busca construir un diálogo intercultural" (Moraes Wichers 2019: 54). Segundo por crear, desde la Arqueología Etnográfica y la Museología Social, una oportunidad de reflexionar sobre los procesos de coleccionismo y de musealización practicados por la entidad.

Está reconocido mundialmente el rol de la FUMDHAM en la conservación y la investigación de un Patrimonio Mundial de inestimable valor científico. Igualmente destaca su actuación respecto al desarrollo local desde los esfuerzos para crear una estructura turística que 
facilite el acceso al parque y los programas de educación patrimonial y capacitación de las comunidades locales como, por ejemplo, el Grupo Cerámica Artesanal Serra da Capivara9.

Ya forma parte del sentido común que, si el patrimonio cultural no le interesa a la gente, poco resultado tendrán los proyectos de gestión iniciados por la administración pública. Por su parte, el IEPA, junto a otras entidades, desarrolló una propuesta de musealización del sitio Rego Grande I/Calçoene basada en estudios de público y teniendo en cuenta los significados y la relación de las comunidades del entorno con su patrimonio. Sin embargo, para la ejecución del proyecto, faltó la voluntad de los políticos de continuarlo, pues les demandaba acciones específicas, algunas para crear y mantener las condiciones necesarias para el acceso al sitio arqueológico, transformándolo en producto turístico factible. Por eso se trata de un caso que expone los usos políticos del patrimonio, volátiles y poco duraderos que suelen cambiar con las gestiones.

La muestra enseña la diversidad de experiencias resultantes de la musealización, integral o parcial, de sitios. En algunos casos, como el paisaje del río Araguaia, las acciones de preservación, investigación y comunicación, integradas, resultan en la musealización de un territorio. En los sitios preparados para la visita, se notan situaciones diversas. Según Marcela Nogueira (2007), en esos contextos las visitas turísticas pueden organizarse de manera sostenible o no. Entre esas, en algunos casos, existe preocupación e interés por parte de las entidades en su planeamiento y en otros no, resultando en daños al patrimonio.

Pese a las especificidades y diferencias, en el conjunto de experiencias aquí enseñado se observa la opción por la museografía in situ, es decir, desde una perspectiva integral se abordan los bienes muebles e inmuebles "de forma que la presentación al público se realice a través de una comunicación directa entre el visitante y la realidad mostrada en su contexto, su autenticidad y su originalidad" (Hernández 2010: 27).
En el MASJ, el MAI, el MHA/FUMDHAM y el proyecto de musealización de Rego Grande I/ Calçoene se observa una mezcla entre ese tipo de museografía y la museografía temática, donde los argumentos y los temas son presentados reuniendo para ello a los objetos que disponen (Ibid. 31). Sin embargo, el único caso que se puede relacionar con el concepto de museo de sitio, es decir, lugar musealizado donde se desarrollan las excavaciones arqueológicas, está vinculado al MHA/FUMDHAM.

La actual coyuntura del sector cultural y de patrimonio en el país sufre cambios dramáticos, resultado de cortes presupuestarios en los últimos 10 años y de alteraciones es las directrices y los ejes de las políticas públicas, promovidas por el gobierno actual. El panorama de la preservación del patrimonio arqueológico empeora por estos recortes en la ciencia y la educación y por los cambios en las leyes ambientales. Por ello, resulta más importante que nunca sumar esfuerzos y aprovechar todas las oportunidades para afrontar los retos. Respecto a la preservación y la puesta en valor de los bienes arqueológicos musealizados, o que se pueden musealizar, es imprescindible crear una agenda conjunta entre las entidades estatales de museos y de patrimonio para mejorar la gestión y las estrategias de socialización de los sitios arqueológicos. Es un primer paso, y por ello crucial, para que la relación entre museos y sitios esté dirigida hacia la construcción de un presente y un futuro más justo, más inclusivo y más sostenible.

\section{Agradecimientos}

Agradezco a Dione Bandeira, Mariana Cabral, Manuelina Cândido, Lucio Leite, Gerson Machado y Daiane Pereira por la información sobre los museos que componen la muestra aquí enseñada, a los miembros de la REMAAE y el GTA/SAB, por su ayuda para recopilar los datos sobre los sitios arqueológicos musealizados ubicados en el territorio nacional. 


\section{Bibliografía}

Bandeira, D. R. y Gusso, L. C. S. (2018): A proteção jurídica do patrimônio arqueológico: o caso dos sambaquis de Joinville. Anais do Congresso de Direito do Patrimônio Cultural, Ouro Preto. 41-48.

Bicho, N. F. (2011): Manual de Arqueologia Pré-Histórica. Ediçoes 70, Lisboa.

Botallo, M.; Piffer, M. y Von Poser, P. (2014). Patrimônio da Humanidade do Brasil: suas riquezas culturais e naturais. UNESCO, París; Editora Brasileira de Arte e Cultura, São Paulo.

Brasil. (2009). Ley n. 1194/09. [URL https://presrepublica.jusbrasil.com.br/legislacao/92498/estatuto-demuseus-lei-11904-09 ] Acceso el 29/07/2021.

Bruno, M. C. de O. (2018). Museus de Arqueologia no Brasil - uma estratigrafia de abandonos e de desafios. In Costa, A. L. A. y Lemos, E. B. R. (orgs.). Anais 200 anos de museus no Brasil: desafios e perspectivas. Brasília: Ibram, p.112-122. Disponible en [URL: https://www.museus.gov.br/wp-content/ uploads/2019/12/Anais-200anosMuseusBrasil_FINAL.pdf] Acceso el 15/03/2020

Cabral, M. T. y Saldanha, J. D. M. (2008a): Paisagens megalíticas na costa norte do Amapá. Revista de Arqueologia, 21: 9-26.

Cabral, M. T. y Saldanha, J. D. M. (2008b): Um sítio, múltiplas interpretações: o caso do chamado "Stonehenge do Amapá. Revista de Arqueologia Pública 3: 7-13.

Cabral, M. T. y Saldanha, J. D. M. (2009): Um sítio, múltiplas interpretações: o caso do chamado "Stonehenge do Amapá. Revista de Arqueologia, 2 (1) jan/jul: 115-123.

Costa, B. R. (2019): Percebendo o sambaqui: simetria aplicada à gestão do patrimônio arqueológico em Joinville. Anais do V Seminário de Preservação de Patrimônio Arqueológico do MAST. Museu de Astronomia e Ciências Afins, Río de Janeiro: 403-414.

Costa, C. A. S. (2017): Um grito de sobrevivência: agenciamento das bases jurídico-legais de endosso institucional para a guarda e pesquisa de acervos arqueológicos e a militância político-acadêmica das comunidades arqueológica e museológica. Revista Arqueologia Pública, 11 (2): 215-253.

Cury, M. X. (2020): Povos indígenas e Museologia - experiências nos museus tradicionais e possibilidades nos museus indígenas. Museu, ação comunitária e descolonização. (B. B. Soares, ed.). ICOM/ICOFOM, París. 354-370.

Ferreira, M. S. (2017): Percursos da memória: narrativas sobre patrimônio no Museu de Arqueologia de Itaipu. Tesis Doctoral. Río de Janeiro: Pontifícia Universidade Católica do Rio de Janeiro.

Figueiredo, s. J. L. y Pereira, E. S. \& Bezerra, M. (coords.). (2010): Projeto Básico e especificações técnicas para elaboração de socialização de sítios arqueológicos na Amazônia: musealização, educação e turismo. Parte 3: Calçoene. UFPA/MPEG/IPHAN/FADESP, Belém.

Gaspar, M.D y Rodrigues, I. M. M. (2020): Coleções etnográficas e Arqueologia: uma relação pouco explorada. Boletim do Museu Paraense Emilio Goeldi, 15 (1): 1-19 [URL https://mail.google.com/ mail/u/0/\#search/pamella/QgrcJHrnqzHZCpnJQNfwMnSCTSMWghCFPRl?projector=1\&messagePa rtId $=0.6]$ Acceso el 20/06/2020

Gonçalves, M. E. (2001): Da "Pré-História" à História do Caso de Foz Côa: Arqueologia, política e participação. In Gonçalves, M. E. (coord.). O caso de Foz Côa: um laboratório de análise sóciopolítica. Edições 70, Lisboa: 27-64.

Gussso, L. C. S. y BANDEIRA, D. R. (2018): A proteção jurídica do patrimonio cultural arqueológico: o caso dos sambaquis de Joinville/SC. Anais do Congresso de Direito do Patrimônio Cultural, Ouro Preto, p.41-48.

Haber, A. (2011): Nometodología Payanesa: notas de metodología indisciplinada (com comentários de Henry Tantalean, Francisco Gil). Revista Chilena de Antropología, 23: 9-49.

Hernández, F. H. (2010): Los museos arqueológicos y su museografía. Ediciones Trea, Gijón.

ICOMOS (1990): Carta de Lausana. [URL https://www.icomos.org/images/DOCUMENTS/Charters/ arch_sp.pdf] Acceso el 22/06/2020

Lourdeau, A. (2019): A Serra da Capivara e os primeiros povoamentos sul-americanos: uma revisão bibliográfica. Boletim do Museu Paraense Emilio Goeldi, Ciências Humanas, 14(2) may/aug. [URL https://www.scielo.br/scielo.php?script=sci_arttext\&pid=S1981-81222019000200367] Acceso el $20 / 06 / 2020$

Machado, E. A. (2013): Preservação do patrimônio arqueológico em Joinville/SC: liquefações contemporâneas. Educação Patrimonial e Arqueologia Pública: experiências e desafios. (Machado, G. \& Souza, F. C. A. \& Steinbach, J., coords.). Casa Aberta Editora, Itajaí: 101-128. 
Martins, A. M. S. (2015): O tronco Macro-Jê: hipóteses e contribuições de Aryon Dall'Igna Rodrigues. Fragmentum, 46 jul/dic.: 101-135.

Martins, D. C. (2017): Plano Museológico: Museu Antropológico da Universidade Federal de Goiás 2018-2021. Universidade Federal de Goiás, Goiânia.

Mignolo, W. D. (2003): Histórias Locais / Projetos Globais: Colonialidade, saberes subalternos e pensamento liminar. UFMG, Belo Horizonte.

Moraes Wichers, C. A. (2019): Sobre a musealização de acervos Iny-Karajá: desafios e possibilidades para uma prática decolonial. Revista Habitus, 17 (1): 53-76. [URL http://seer.pucgoias.edu.br/index.php/ habitus/article/view/7258] Acceso el 30/06/2020

Moraes Wichers, C. A. y Saladino, A. (2015): Los museos van por aquí y el patrimonio arqueológico por allí: los retos para la continuación de los procesos de preservación en Brasil. Revista Memorias, 27: 107-144.

Nogueira, M. N. (2007): Turismo e Arqueologia na Amazônia: planejamento e visitação de sítios arqueológicos na região da Serra dos Martírios. Universidade Federal do Pará, Belém.

Saladino, A. (2015): Museus e Arqueologia: algumas reflexões sobre preservação e valorização de bens arqueológicos. Revista Tempo Amazônico. 3 (1): 159-177. [URL http://rj.anpuh.org/resources/ download/1482451237_ARQUIVO_Texto9ArtigodeAlejandraSaladinoFinalizado.pdf ] Acceso el $30 / 06 / 2020$

Saladino, A. (2013/2014): IPHAN, arqueólogos e patrimônio arqueológico brasileiro. Revista de Arqueologia, 26/27 (1/2) [URL https://revista.sabnet.org/index.php/SAB/article/view/381] Acceso el 11/03/2020

Sanabria, I. S. B. (2018): A produção de discursos sobre Homem e Humanismo no Museu do Homem Americano e no Musée de l'Homme. Tesis doctoral. Universidade de Campinas, Campinas.

Saladino, A. (2015). Museus e Arqueologia: algumas reflexões sobre preservação e valorização dos bens arqueológicos. Revista Tempo Amazônico, 1 jul./dez.: 159-177.

Saladino, A. \& Castillo Mena, A. (2018): La relación entre el Instituto Pretos Novos y las comunidades em el contexto del Porto Maravilha, Río de Janeiro, Brasil. E-Cadernos, Cadernos CES, 30: 76 - 99 [URL https://journals.openedition.org/eces/3626] Acceso el 20/03/2020

Saladino, A. (2019): Arqueología y sociedad en Brasil: una mirada sobre la socialización y la preservación del patrimonio arqueológico desde la educación patrimonial. Revista OTARQ - Otras Arqueologías, 4: 251-265. [URL http://revistas.jasarqueologia.es/index.php/otarq/article/view/186] Acceso el 25/03/2020

Saladino, A.; Barata, C. E. y Biserra, N. F. (2013): Longe das vistas: o Recolhimento de Santa Teresa na Freguesia de São Sebastião de Itaipu. Caderno Socioambiental, 1 (1) 43- 51.

Saladino, A. \& Barata, C. E. y Biserra, N. F. (2014): Atas do Seminário Processos de Musealização: um seminário de investigação internacional. Universidade do Porto, Porto. 224-251. [URL https://ler.letras. up.pt/uploads/ficheiros/13493.pdf] Acceso el 30/03/2020

Saladino, A.; Campos, L. y Carvalho, C. R. (2020): Reflexões sobre a prática arqueológica no Brasil do século XXI. Revista Habitus, 18 (1): 52-69.

Saladino, A. y Castillo Mena, A. (2018): Prospecções sobre a relação entre as comunidades do bairro Reis Católicos (Alcalá de Henares, Madrid) e seus bens arqueológicos. Cadernos de Sociomuseologia, 56 (12): 87-108. [URL https://revistas.ulusofona.pt/index.php/cadernosociomuseologia/article/view/6530] Acceso el 22/03/2020

Saladino, A. y Costa, C. A. S. (2015): E agora, José? Reflexões sobre o estado da arte do patrimonio arqueológico no Brasil. Patrimônio Cultural, direito e meio ambiente: um debate sobre a globalização, cidadania e sustentabilidade (Campos, J. B.; Preve, D. R. y Souza, I. F., orgs.). Multideia Editora, Curitiba: 169-190.

Saladino, A. y Laroque, E. B. (2020): Museu de Arqueologia de Itaipu (MAI), Niterói, Brasil: desafios do século XXI para um museu e suas comunidades. Museus, Turismo e Património em Ibero-América. (Espina Barrio, A. \& Corrêa, L.N., eds.) Instituto de Investigaciones Antropológicas de Castilla y León, Universidad de Salamanca, Salamanca: 71-87.

Saladino, A.; Moraes Wichers, C. A. y Sanabria, I. B. (2015): San Miguel de Misiones y Serra de Capivara, Brasil: tensiones entre políticas de patrimonialización y comunidades locales. Actas del II Congreso Internacional de Buenas Prácticas en Patrimonio Mundial: Personas y Comunidades. Universidad Complutense de Madrid, Madrid: 81-106.

Saladino, A. y Polo, M. A. (2017): Acervo Arqueológico. Dicionário do Patrimônio Cultural. [URL http://portal.iphan.gov.br/dicionarioPatrimonioCultural/detalhes/65/acervo-arqueologico] Acceso el $01 / 07 / 2020$ 
Silva, D. E. F. (2014): O programa estadual de preservação do patrimônio arqueológico e a proteção do passado no Amapá (2005/2012). Anais do XVI Encontro Regional de História da ANPUH-Rio: saberes e práticas cientificos. ANPUH-Rio, Río de Janeiro: 1-11.

Silva, D. E. F. (2016): Sobre as "pedras famosas de Calçoene: reflexões a partir da arqueologia etnográfica na Amazônia. Máster em Antropología. Universidad Federal do Pará, Belém.

Souza, F. C. A. y Weiers, M. S. (2010): Uma experiência de educação patrimonial no Museu do Sambaqui de Joinville: provocando sensações e estimulando percepções. Revista CPC, 9: 25-41.

Tebaldi Toledo, G. (2017): Musealização da Arqueologia e Conservação Arqueológica: experiências e perspectivas para a preservação patrimonial. Tesis Doctoral. São Paulo: Universidade de São Paulo. [URL https://www.teses.usp.br/teses/disponiveis/71/71131/tde-05062018-085208/pt-br.php]

Acceso el 01/07/2020.

Unesco. (1956): Recomendaciones de Nueva Delhi. [URL http://portal.unesco.org/es/ev.php-URL_ ID=13062\&URL_DO=DO_TOPIC\&URL_SECTION=201.html ] Acceso el 29/07/2021. 
